Educandum: Volume 6 Nomor 1 Juni 2020

\title{
INDEKS KARAKTER SISWA SMA DI PROVINSI MALUKU
}

\author{
Abdul Rahman Arsyad *
}

Balai Peneitian dan Pengembangan Agama Makassar Jl. AP.Pettarani No. 72 Makassar Email: rahmanarsyad17@gmail.com INFO ARTIKEL ABSTRAK

Penelitian Indeks Karakter Siswa SMA, dengan menelusuri berbagai dimensi Religiusitas, Nasionalisme, Kemandirian, Gotong royong, dan Integritas, yang dilaksanakan pada 11 sekolah SMA pada tiga Kabupaten di Provinsi Maluku. Penelitian ini adalah penelitian deskriptif dengan menggunakan pendekatan kualitatif dan kuantitatif. Pengumpulan data dilakukan dengan cara observasi, wawancara, dan angket. Adapun Hasil penelitian adalah melihat berbagai dimensi danfaktor yang mempengaruhiKarakter Siswa SMA. Responsibiliti siswa kelas XI terhadap dimensi dan aspekreligiusitas (kepercayaan, sosial dan keagamaan); nasionalisme (cinta dan bangga terhadap tanah air, kepekaan psikologi dan komitmen terhadap negara); kemandirian (kemandirian dirumah dan sekolah); gotong royong (kepedulian lingkungan, meraih kesuksesan bersama, interaksi sosial yang saling membutuhkan serta mencari solusi secara kolektif); dan integritas (kejujuran, amanah, hormat menghormati dan saling menghargai, bertanggungjawab dan adil). Tergolong terkategori SEDANG (3,48\%), sehingga perlu ditingkatkan komunikasi secara sinergi antara pihak lembaga pendidikan sekolah dan keluarga (orang tua), agar dapat memberikan dukungan atau penguatan dalam pembiasaansecara berkesinambungan. Sehingga, aplikasinya dapat terwujud dalam kehidupan sehari-hari di lingkungan sekolah, keluarga dan masyarakat. Adapun yang mempengaruhi karakter siswa, yaitu: Sikap dan

Kata Kunci: Indeks, Karakter, Siswa SMA, Maluku prilaku, pemahaman dan pengalaman agama orang tua, guru dan masyarakat sangat berpengaruh dalam membentuk perilaku siswa. Kegiartan keagamaan yang dilaksnakan diluar sekolah sangat berperan dalam memupuk sikap religiusitas.

\section{ABSTRACT}

Research on High School Student Character Index, by exploring various dimensions of Religiosity, Nationalism, Independence, Mutual Cooperation, and Integrity, carried out in 11 high school schools in three districts in Maluku Province. This research is a descriptive study using qualitative and quantitative approaches. Data collection is done by observation, interviews, and questionnaires. The results of the study are looking at various dimensions and factors that influence the character of high school students. The responsibility of class XI students on the dimensions and aspects of religiosity (beliefs, social and religious); nationalism (love and pride in the homeland, psychological sensitivity and commitment to the country); independence (independence at home and school); mutual cooperation (environmental concern, achieving mutual success, social interactions that need each other and seek solutions collectively); and integrity (honesty, trustworthiness, respect for respect and mutual respect, responsibility and fairness). It is classified as MEDIUM (3.48\%), so communication needs to be improved in synergy between the school education institution and the family (parents), so that it can provide support or reinforcement in a sustainable manner. So, the application can be realized in everyday life in the school, family and community environment. As for those that influence the character of students, namely: Attitudes and behaviors, understanding and religious experience of parents, teachers and society is very influential in shaping student behavior. The religious activities carried out outside the school play an important role in fostering a attitude of religiosity. 


\section{PENDAHULUAN}

Pendidikan karakter telah diberikan dalam penyelenggaraan pendidikan dasar dan menengah untuk menyeimbangkan dengan proporsi pendidikan intelektual. Kesadaran sekaligus usaha pemusatan pendidikan karakter di jantung pendidikan nasional semakin kuat ketika pada tahun 2010 pemerintah Indonesia mencanangkan sekaligus melaksanakan kebijakan Gerakan Nasional Pendidikan Karakter berlandaskan Rencana Aksi Nasional (RAN) Pendidikan Karakter Bangsa. Ada Gerakan Penguatan Pendidikan Karakter (PPK) dengan mengindahkan asas keberlanjutan dan kesinambungan (Hendarman, dkk, 2017).

Tahun 2017 Puslitbang pendidikan agama dan Keagamaan telah melakukan survei integritas peserta didik di 10 provinsi yang kemudian dengan data survei itu disusun Indeks Integritas peserta didik Tahun 2017. Kemudian tahun 2018 Puslitbang Pendidikan Agama dan Keagamaan melakukan penyusunan indeks integritas peserta didik di 34 provinsi sebagai penyempurnaan kegiatan penyusunan indeks integritas peserta didik tahun2017. Selanjutnya tahun 2019, Puslitbang Pendidikan Agama dan Keagamaan akan melakukan penyusunan indeks karakter peserta didik tahun 2019.

Dengan dibuatnya indeks peserta didik, akan terlihat pencapaian indeks karakter peserta didik secara nasional dan masing-masing provinsi yang dilihat dari masing-masing dimensi karakter peserta didik. Melalui indeks masing-masing provinsi, akan terlihat kontribusi masingmasing provinsi terhadap capaian tingkat karakter peserta didik secara nasional. Selain itu, daerah yang memperoleh hasil indeks tinggi dapat diberi apresiasi berupa penghargaan kepada lembaga pendidikan sehingga termotivasi mempertahankan dan meningkatkan karakter peserta didik. Sebaliknya, daerah dengan memperoleh indeks rendah dapat menggunakan hasil indeks karakter untuk memperbaiki kekurangan secara terarah dan terprogram.
Permasalahannya adalah sampai saat ini, berdasarkan hasil penelusuran literatur, di Indonesia belum ada instrumen atau alat ukur yang baku untuk mengukur tingkat karakter peserta didik. Menyadari pentingnya karakter peserta didik dalam kehidupan individu dan bermasyarakat serta belum adanya alat ukur atau instrumen yang baku untuk mengetahui tingkat karakter peserta didik, maka perlu dilakukan penelitian untuk mengembangkan instrumen karakter personal (personal character scale). Alat ukur ini akan memiliki kemampuan prediktif terhadap peserta didik dalam berbagai situasi untuk menjalankan tugas dan tanggung jawabnya, apakah yang bersangkutan memiliki karakter yang rendah, sedang, atau tinggi.

\section{Masalah Penelitian}

Permasalahan penelitian ini adalah 1) Bagaimana kualitas karakter peserta didik pada jenjang pendidikan menengah, 2) Seberapa besar indeks karakter peserta didik pada jenjang pendidikan menengah secara nasional maupun pada level provinsi, 3) Faktor-faktor yang mempengaruhi karakter peserta didik.

\section{Tujuan dan Kegunaan Penelitian}

Secara umum, tujuan penelitian ini adalah untuk mengembangkan alat ukur atau instrumen karakter pribadi yang mengukur karakter personal sebagai trait (sifat). Secara spesifik, penelitian ini bertujuan untuk mengembangkan alat ukur yang mampu memprediksi traits atau sifatsifat yang membentuk karakter personal. Secara khusus, tujuan penelitian ini adalah untuk mengetahui tingkat karakter peserta didik pada jenjang pendidikan menengah secara nasional maupun level provinsi.

Kegunaan Penelitian; ini diharapkan mampu memberikan manfaat baik secara praktis maupun teoritik. Manfaat praktis yang diharapkan dapat diambil dari penelitian ini adalah terukurnya indeks karakter peserta didik yang dapat dijadikan 
salah satu bahan perumusan kebijakan pada satuan lembaga pendidikan, Kementerian Agama Kabupaten/Kota, Kementerian Agama Provinsi, Direktorat Pendidikan Madrasah, Direktorat Pendidikan Agama Islam, Direktorat Pendidikan Agama pada masing-masing Ditjen Bimbingan Masyarakat, Badan Litbang dan Diklat, Kementerian Pendidikan dan Kebudayaan. Sedangkan secara teoritis, penelitian ini diharapkan mampu memberikan sumbangan referensi ilmiah tentang studi tentang karakter dan indeks karakter, yang selanjutnya dapat dikembangkan untuk penelitian- penelitian karakter dengan focus kajian yang berbeda.

\section{KAJIAN TEORI \\ Definisi Karakter}

Saligmen, tokoh utama psikologi positif menyebutkan bahwa karakter personal yang positif merupakan salah satu dari tiga pilar psikologi positif selain pengalaman subyektif yang positif dan komunitas dan istitusi yang positif. Tiga pilar psikologi positif ini saling berkaitan satu sama lain dalam kaitannya dengan bagaimana manusia meraih kebahagiaan di dunia dan tentu saja di akhirat (Aryani,2017; Gable \& Haidt, 2005).

Religiusitas dapat diartikan kesalehan atau kondisi yang cenderng agamis pada individu (Paloutzian \& Park, 2005). Sebagai sebuah konsep laten yang mengukur perilaku keagamaan individu, relijiusitas kerapkali dikaitkan dengan banyak perilaku seperti kesehatan mental, karakter, toleransi atau intoleransi dan lainlain. Bahkan dalam sejumlah riset, relijiusitas menjadi penanda kesehatan mental seseorang (Cotton, McGrady \& Rosenthal, 2010). Dalam konteks masyarakat Indonesia, agama atau relijiusitas merupakan konsep sangat penting dalam kehidupan sehari-hari. Bahkan, disebutkan bahwa agama merupakan unsur paling penting di atas anasir kehidupan lainnya (Hasan, 2012).

Dalam kajian psikologi sosial khususnya, nasionalisme sangat erat kaitannya dengan identitas dan kepribadian (Cacioppo et al, 2014). Studi tentang identitas diawali dari studi tentang konsep diri atau identitas personal (Sutton \& Douglas, 2013). Konsep diri mengandung tiga dimensi yaitu bagaimana seseorang melihat dirinya, bagaimana orang lain melihat dirinya dan bagaimana seseorang berimajinasi tentang dirinya di masa depan(Capitanio, 2012).

Kemandirian merupakan salah satu nilai yang memberikan pengalaman subyektif kepada setiap anak didik, selain rasa memiliki dan keyakinan akan kemampuan individual untuk mengejar sukses. Memberikan pengalaman subyektif melalui kesempatan untuk menjadi mandiri merupakan proses dan mekanisme psikologis yang signifikan dalam rangka memunculkan kekuatan karakter personal yang positif (Linley \& Joseph, 2012).

Gotong-royong merupakan suatu konsep yang menggambarkan semangat dan prinsip kolektivisme suatu masyarakat. Dalam kajian psikologi lintas budaya, kolektivisme adalah lawan dari individualisme. Keduanya merupakan variasi yang bersifat budaya dan individual. Dengan kata lain, semangat kolektivisme secara budaya menggambarkan bahwa individu atau kumpulan individu memiliki semangat inklusif yang interdependen sedangkan semangat individualisme menggambarkan bahwa individu atau kumpulan individu memiliki semangat dan jiwa independen satu sama lain. Triandis menyebutkan bahwa jiwa kolektivisme pada umumnya dapat ditemukan pada masyarakat Timur termasuk Indonesia sedangkan jiwa individualisme pada umumnya ditemukan pada masyarakat Barat (Gelfand, Triandis \& Chan, 1996; Harry C. Triandis, 2018; Harry Charalambos Triandis, 1990).

Integritas adalah komitment terhadap lima nilai fundamental, yaitu kejujuran, keadilan, kepercayaan, tanggungjawab dan penghormatan. Kelima nilai ini merupakan kode moral atau kebijakan etis yang harus dimiliki seseorang dalam berbagai bidang 
kehidupan termasuk kehidupan siswa di sekolah maupun di luar sekolah (The University of Adelaide, 2011; The Center of Academic Integrity, 2005).

\section{Metodologi Penelitian}

Jenis penelitian adalah penelitian pengabungan (mix methode), dengan pendekatan kuantitatif dan kualitatif. Penelitian dilaksanakan di Kabupaten Seram Bagian Barat, Maluku Barat Daya, dan Maluku Tengah Provinsi Maluku.

Menurut Sugiyono (2012:39) metode penelitian dapat digabungkan dengan catatan penelitian kuantitatif menggunakan teknik pengumpulan data dengan angket/kuesioner, data yang diperoleh adalah data kuantitatif, selanjutnya untuk memperkuat dan mengecek validitas data hasil kuisioner tersebut maka dapat dilengkapi dengan observasi atau wawancara kepada responden yang telah memberikan angket tersebut, atau orang lain yang memahami masalah yang diteliti (penelitian kualitatif).

Analisis data dilakukan dengan terlebih dahulu mentabulasi hasil angket berdasarkan variabel yang terurai pada beberapa indikator. Kemudian dilakukan distribusi frekuensi dengan menggunakan aplikasi SPSS versi 16.0 untuk melihat banyaknya pilihan pada skala pengukuran dan rata-rata pengukuran (mean), dan selanjutnya diinterpretasi berdasarkan skala interval yang telah ditentukan.

\section{HASIL DAN PEMBAHASAN \\ Gambaran Umum Lokasi Penelitian}

Kabupaten Seram Bagian Barat memiliki 47 (38 SMA, 9 MA) lembaga pendidikan tingkat menengah $(\mathrm{N} / \mathrm{S})$. Alat transportasi darat yang digunakan masyarakat setempat pada umumnya menggunakan angkot dan ojek. Sedangkan untuk lintas pulau masyarakat menggunakan fery dan speed. Adapun jarak tempuh dari pelabuhan waipirit ke ibu kota kabupaten $\pm 40 \mathrm{Km}\left(1 \frac{1}{2}\right.$ jam $)$.

Pada umumnya siswa ke sekolah dengan jalan kaki, dibanding menggunakan alat transportasi angkot/ojek. Hal ini disebabkan adanya keterbatasan finansial yang dimiliki siswa.

Kabupaten Maluku Barat Daya memiliki 21 SMA (N/S) yang tersebar di berbagai pulau. Alat transportasi yang digunakan masyarakat dominan menggunakan speed dan kapal. Bahkan ada satu SMA 1 Ilwaki lebih dekat lewat Kupang dibanding dari Tiakur.Begitupun halya dengan SMA Kristen Aprian dan SMA 1 PP Babar yang berada di daerah Damer. Transportasi laut (kapal) hanya 1 kali penyeberangan dalam seminggu.

Masyarakat setempat dominan darat(motor/ojek) dibanding angkot dan mayoritas penduduk yang bermukim di daerah Tiakur adalah ASN/TNI/Polisi dibanding penduduk biasa.

Kabupaten Maluku Tengah (salahutu) berbatasan dengan Kota Ambon sedangkan untuk menuju ke Ibu Kota Kabupaten (Masohi) dengan menggunakan transportasi laut (kapal cepat). Adapun sarana transportasi masyarakat yang digunakan adalah angkot, ojek, kapal cepat dan speed.

\section{Lembaga Pendidikan}

Provinsi Maluku merupakan daerah kepulauan, dimana memiliki 11 Kabupaten/Kota dan memiliki jumlah lembaga pendidikan tingkat menengah 341 buah, diluar sekolah kejuruan (SMK). Daerah/wilayah penelitian terdapat tiga lokasi, diantaranya: Kabupaten Seram Bagian Barat, Maluku Barat Daya, dan Maluku Tengah.

Lembaga pendidikan tingkat menengah (SMA/MA) yang tersebar di Propinsi Maluku memiliki jumlah yang bervariatif, begitupun dengan status sekolah. Dari $11 \mathrm{Kab} /$ Kota yang memiliki jumlah sekolah SMA/MA yang terbanyak yaitu: Kabupaten Maluku Tengah SMA 78 dan MA 21. Sedangkan yang paling sedikit jumlah sekolah SMA/MA adalah Kabupaten Kepulauan Aru, yaitu SMA 11 dan MA 1 lembaga. 
Lembaga pendidikan madrasah (MA) yang tersebar di Provinsi maluku tidak terbilang banyak dibanding daerah luar Maluku. Terdapat dua Kabupaten yang belum memeiliki lembaga madrasah (MA),

Tabel l. Jumlah Sekolah SMA/MA berdasarkan Kota/Kabupaten

\begin{tabular}{|c|c|c|c|c|}
\hline \multirow{2}{*}{ NO } & \multirow{2}{*}{ КАВ/KOTA } & \multicolumn{3}{|c|}{ S E K O L A H } \\
\hline & & SMA & MA & JML \\
\hline 1. & KABUPATEN BURU & 15 & 4 & 19 \\
\hline 2. & KAB. BURU SELATAN & 15 & 1 & 16 \\
\hline 3. & KAB. KEPULAUAN ARU & 11 & 1 & 12 \\
\hline 4. & KOTA AMBON & 34 & 6 & 40 \\
\hline 5. & KABUPATEN TUAL & 11 & 3 & 14 \\
\hline 6. & KAB. MALUKU TENGAH & 78 & 21 & 99 \\
\hline 7. & KAB. MALUKU TENGGARA & 18 & 4 & 22 \\
\hline 8. & KAB. MALUKU TENGGARA BARAT & 21 & - & 21 \\
\hline 9. & KAB. SERAM BAGIAN BARAT & 38 & 9 & 47 \\
\hline 10. & KAB. SERAM BAGIAN TIMUR & 22 & 8 & 30 \\
\hline 11. & KAB. MALUKU BARAT DAYA & 21 & - & 21 \\
\hline & J U M L A H & 284 & 57 & 341 \\
\hline
\end{tabular}

Berdasarkan jumlah lembaga pendidikan pada tingkat menengah yang tersebar di beberapa kota/kabupaten di Provinsi Maluku secara persentase sekolah SMA 284 (83\%) dan MA 57 (17\%). yaitu: Kabupaten Maluku Tenggara Barat dan Maluku Barat Daya. Maluku Barat Daya adalah daerah/wilayah pemekaran dari kabupaten Maluku Tenenggara Barat.

Tabel 2. Jumlah Sekolah dan Siswa Berdasarkan Sampel Penelitian

\begin{tabular}{|c|c|c|c|c|c|c|}
\hline \multirow{2}{*}{ NO } & \multirow{2}{*}{ KAB } & \multirow{2}{*}{ SEKOLAH } & \multicolumn{4}{|c|}{ JUMLAH SISWA } \\
\hline & & & $\mathbf{X}$ & $\mathbf{X I}$ & XII & JML \\
\hline \multirow{5}{*}{1.} & \multirow{5}{*}{ SBB } & SMA PGRI 3 Kairatu & 28 & 34 & 29 & 91 \\
\hline & & SMAN 1 Seram Barat & 220 & 220 & 204 & 644 \\
\hline & & SMA PGRI Pelita Jaya & 77 & 61 & 53 & 191 \\
\hline & & SMAN 4 Seram Barat & 146 & 117 & 95 & 358 \\
\hline & & SMA Muhammadiyah Patinia & 19 & 11 & 39 & 67 \\
\hline \multicolumn{3}{|c|}{ J U M L A H } & 490 & 443 & 420 & 1.353 \\
\hline \multirow{3}{*}{2.} & \multirow{3}{*}{ MBD } & SMA Negeri Tiakur & 198 & 132 & 144 & 474 \\
\hline & & SMA Negeri 1 Lemoko & 188 & 141 & 117 & 446 \\
\hline & & SMA Negeri 1 Moa lakor & 34 & 40 & 25 & 99 \\
\hline \multirow{4}{*}{3.} & & & 420 & 313 & 286 & 1.019 \\
\hline & \multirow{3}{*}{$\begin{array}{l}\text { MALUKU } \\
\text { TENGAH }\end{array}$} & SMA Negeri 5 Salahutu & 43 & 22 & 30 & 95 \\
\hline & & SMA Negeri 3 Salahutu & 130 & 112 & 120 & 362 \\
\hline & & SMA Negeri 1 Salahutu & 193 & 204 & 150 & 547 \\
\hline \multicolumn{3}{|c|}{ JUMLAH } & 366 & 338 & 300 & 1.004 \\
\hline \multicolumn{7}{|c|}{ Berdasarkan dari jumlah sampel SMA terdapat 1.276 Siswa kelas X } \\
\hline \multicolumn{7}{|c|}{ Berdasarkan dari jumlah sampel SMA terdapat 1.094 Siswa kelas XI } \\
\hline \multicolumn{7}{|c|}{ Berdasarkan dari jumlah sampel SMA terdapat 1.006 Siswa kelas XII } \\
\hline \multicolumn{7}{|c|}{ Berdasarkan dari jumlah sampel SMA dari tiga Kabupaten terdapat 3.376 Siswa } \\
\hline
\end{tabular}

Kabupaten Seram Bagian Barat terdapat lima sekolah SMA, Maluku Barat Daya tiga SMA dan Maluku Tengah

Penelitian dilaksanakan pada tiga Kabupaten yang tersebar di Provinsi Maluku, yaitu: Kabupaten Seram Bagian Barat, Maluku Barat Daya, dan Maluku Tengah dengan berbagai sekolah SMA

(N/S), siswa, dan tingkat. 
berbagai sekolah pada masing-masing sekolah (SMA) memiliki jumlah siswa yang bervariatif, yaitu: kelas X1.276 (38\%), XI 1.094 (32\%), dan XII1.006 (30\%).

Berdasarkan sampel nasional, Provinsi Maluku3kabupaten, 11 SMA, dan 110 respondenmerupakan sasaran penelitian, yaitu: Kabupaten Seram Bagian Barat (5 SMA) dan Maluku Barat Daya (3SMA), dan Kabupaten Maluku Tengah (3 SMA) dengan menggunakan waktu 16 hari.

\section{DIMENSI ANALISIS}

Berdasarkan dari hasil analisis tabulasi, dengan melihat berbagai indikator pada masing-masing variabel. Maka, tergambar tingkat karakteristik siswa SMA di Kabupaten Maluku Barat Daya, Seram Bagian Barat, dan Maluku Tengah secara jelas. Selanjutnya hasil analisi tabulasi akan diuraikan secara riil berdasarkan indikator dan aspek sebagai berikut:

\section{Religiusitas}

Pada aspek religiusitas terdapat lima bahagian yang dianalisis untuk mengukur tingkat karakter siswa,diantaranya: Kepercayaan, Praktik Personal, Sosial, Kebanggaan dan Identitas Beragama.

\begin{tabular}{clr}
\hline NO & \multicolumn{1}{c}{ INDIKATOR } & TINGKAT \\
\hline A1 & $\begin{array}{l}\text { Saya percaya bahwa Tuhan itu ada } \\
\text { A2 }\end{array}$ & $\begin{array}{l}\text { Saya percaya bahwa kitab suci agama saya berisi } \\
\text { pedoman hidup }\end{array}$ \\
A3 & $\begin{array}{l}\text { Saya percaya bahwa setiap kebaikan dan keburukan } \\
\text { akan dibalas }\end{array}$ & 3,98 \\
& Kepercayaan & 3,64 \\
\hline
\end{tabular}

Berdasarkan tabel diatas, menunjukkan bahwa karakter Siswa SMA dengan melihat kepercayaan terhadap Tuhan, Kitab Suci, dan Akhlak, merupakan konsep kekuatan bagi semua umat beragama dalam meyakini keberadaan sang pencipta, sehingga semua umat manusia patut meyakini keberadaannya.

Kitab suci merupakan pedoman hidup manusia, dimana konsep-konsep keselematan telah termaktub pada kitab suci pada masing-masing agama. Dari ketiga indikator kepercayaan diatas, para siswa telah memahami dampak kebaikan dan keburukan, walaupun dalam aplikasinya belum dapat di implementasikan dilingkungan keluarga, sekolah dan masyarakat secara maksimal. Dengan melihat ketiga indikator kepercayaan, menunjukkan karakter siswa terkategori Tinggi.

\begin{tabular}{rlr}
\hline NO & \multicolumn{1}{c}{ INDIKATOR } & TINGKAT \\
\hline A4 & Saya rutin beribadah di tempat ibadah & 3,35 \\
A5 & Saya rutin membaca kitab suci & 3,33 \\
A6 & Saya bersungguh-sungguh mempelajari ajaran agama & 3,71 \\
A7 & Saya mengamalkan ajaran kitab suci & 3,45 \\
A8 & Saya berdoa setiap memulai dan mengakhiri kegiatan & 3,60 \\
& $\quad$ Praktik Personal & 3,49 \\
\hline
\end{tabular}

Secara personal, para siswa telah mengaplikasikan ritual ibadah yang diajarakan atau yang diperintahkan pada masing-masing agama. Walaupun pada 
kenyataannya pengetahuan dan kemampuan dalam melaksanakan ibadah dan membaca kitab suci belum dapat diamalkan secara rutin.

Pada prinsipnya, responden (siswa) masih membutuhkan penguatan agar dapat mengaktualisasikan perintah agama terutama pada lingkungan keluarga. Karena indikator diatas merupakan landasan/acuan yang sangat penting bagi semua manusia. Maka, peran keluarga sangat-sangat penting melakukan suatu pembiasaan, agar siswa dapat mengaktualisasikan dengan baik. Berdasarkan indikator diatas, menunjukkan tingkat karakter siswa dalam mengaktualisasikan atau mempraktekkan secara rutin terkategori Sedang.

\begin{tabular}{clr}
\hline NO & \multicolumn{1}{c}{ INDIKATOR } & TINGKAT \\
\hline A9 & Saya peduli terhadap nasib semua umat beragama & 3,32 \\
A10 & Saya bersedia bergaul dengan tetangga beda agama & 3,37 \\
A11 & Saya bersedia bekerjasama dengan orang beda agama & 3,34 \\
A12 & Saya mencintai kedamaian antar umat beragama & 3,80 \\
A13 & Saya membenci kekerasan bernuansa agama \\
A14 & Saya bersahabat dengan siapapun tanpa membedakan & 3,57 \\
& agama dan keyakinan & 3,67 \\
A15 & $\begin{array}{l}\text { Saya menilai prestasi orang lain tanpa membedakan } \\
\text { agama dan keyakinan }\end{array}$ & 3,44 \\
A16 & $\begin{array}{l}\text { Saya tidak pernah memaksakan agama/keyakinan saya } \\
\text { kepada orang lain }\end{array}$ & 3,55 \\
& $\quad$ Praktik Sosial & 3,51 \\
\hline
\end{tabular}

Pengaktualisasian sosial keagamaan responden (siswa) secara keseluruhan masih pada tataran konsep (teori). Hal ini, dikarenakan pengetahuan dan pengalaman siswa masih sangat terbatas. Sehingga untuk dapat memahami memerlukan proses yang panjang. Secara tidak sengaja dari delapan indikator diatas, para siswa sudah pernah mengaplikasikan di lingkungan keluarga, sekolah dan masyarakat.

Hal semacam ini, tidak terlepas penguatan yang bersumber dari lingkungan keluarga, masyarakat dan sekolah. Sehingga perlu adanya penguatan dalam bentuk pembiasaan secara personal. Secara keseluruhan tingkat karakter siswa dalam mengaktualisasikan terkategori Sedang.

\begin{tabular}{clr}
\hline NO & \multicolumn{1}{c}{ INDIKATOR } & TINGKAT \\
\hline A17 & $\begin{array}{l}\text { Saya siap membela agama yang dinistakan pihak lain } \\
\text { sesuai prosedur hukum }\end{array}$ & 3,48 \\
A18 & $\begin{array}{l}\text { Saya percaya diri mengamalkan ajaran agama yang saya } \\
\text { anut }\end{array}$ & 3,74 \\
A19 & $\begin{array}{l}\text { Saya merasa nyaman karena agama saya adalah yang } \\
\text { paling benar }\end{array}$ & 3,42 \\
A20 & $\begin{array}{l}\text { Saya kagum dengan ajaran agama yang membuat hidup } \\
\text { saya lebih baik } \\
\text { A21 }\end{array}$ & $\begin{array}{l}\text { Saya menilai benar-salah dan baik-buruk berdasarkan } \\
\text { ajaran agama }\end{array}$ \\
$\quad$ Kebanggaan Baragama & 3,71 \\
\hline
\end{tabular}

Perlu dipahami bahwa semua manusia memiliki sifat keegoan yang berbeda-beda.
Dalam mempertahankan sesuatu yang sifatnya prinsipil terkadang disitulah 
muncul keegoan, apalagi kalau terkait dengan nilai-nilai keagamaan. Apalagi usia muda (siswa SMA) sangat mempengaruhi dalam mengambil suatu kesimpulan.

Dari lima indikator diatas, menunjukkan bahwa responden dalam menilai kekurangan dan kelebihan berdasarkan ajaran agama, secara objektive belum dapat diimplementasikan secara maksimal. Pada umumnya ummat beragama memiliki kebanggaan dalam meyakini dan mempercayai ajaran-ajaran yang dianut. Maka, tingkat karakter terkategori Sedang.

\begin{tabular}{clr} 
NO & \multicolumn{1}{c}{ INDIKATOR } & TINGKAT \\
\hline A22 & $\begin{array}{l}\text { Saya memutuskan berbagai persoalan berdasarkan } \\
\text { tuntunan agama }\end{array}$ & 3,14 \\
A23 & Saya tidak bisa dipisahkan dari agama yang saya anut & 3,79 \\
& \multicolumn{1}{c}{ Identitas Beragama } & 3,46 \\
\hline
\end{tabular}

Berbicara masalah keyakinan, semua responden (siswa) memiliki pondasi yang sangat kuat dalam meyakini ajaran agama masing-masing. Pada prinsipnya, penguatan dapat terwujud, karena adanya pembiasaan yang sering dijumpai, di lingkungan keluarga, sekolah dan masyarakat. Secara keseluruhan tingkat karakter siswa dalam identitas beragama pada aspek religiusitas terkategori Sedang.

Dari berbagai indikator pada variabel Religiusitas menunjukkan bahwa, tingkat karakter siswa terkategori Sedang $(3,55)$.

\section{Nasionalisme}

\begin{tabular}{llr}
\hline NO & \multicolumn{1}{c}{ INDIKATOR } & TINGKAT \\
\hline B1 & Saya marah ketika lambang negara dilecehkan & 3,75 \\
B2 & Saya mengikuti upacara bendera di sekolah & 3,87 \\
B3 & Saya melakukan sikap hormat saat bendera dikibarkan & 3,70 \\
B4 & Saya menyanyikan lagu kebangsaan Indonesia Raya & 3,65 \\
B5 & dengan hidmat & 3,10 \\
B6 & Saya merasa penting belajar sejarah perjuangan bangsa & 3,79 \\
B7 & Saya merasa senang Indonesia jadi juara dalam kejuaraan & 3,92 \\
& $\quad$ internasional & 3,68 \\
\hline
\end{tabular}

Berdasarkan indikator diatas, menunjukkan bahwa siswa memiliki jiwa nasionalisme yang terbangun melalui lingkungan sekolah. Ini dikarenakan pihak lembaga pendidikan SMA memiliki program dan aturan, dimana siswa memiliki kewajiban untuk melaksanakan aturan yang ditetapkan pihak sekolah.

Namun, masih terdapat sebahagian siswa yang belum serius untuk mempelajari lebih dalam tentang sejarah perjuangan bangsa. Ini disebabkan, karena pada umunya siswa yang dijadikan sebagai responden adalah dominan jurusan MIPA. Tetapi hal ini tidak mengurangi nilai kecintaan siswa terhadap tanah air. Sehingga, tingkat karakter nasionalisme siswa pada indikator cinta tanah air terkategori Sedang. 


\begin{tabular}{clc}
\hline NO & \multicolumn{1}{c}{ INDIKATOR } & TINGKAT \\
\hline B8 & Saya bangga menjadi orang Indonesia & 3,98 \\
B9 & Saya bangga dengan tanah air Indonesia & 3,49 \\
B10 & $\begin{array}{l}\text { Saya lebih senang produk anak bangsa dibanding produk } \\
\text { luar negeri }\end{array}$ & 3,55 \\
B11 & Saya yakin Indonesia akan menjadi negara super power & 3,75 \\
B12 & Saya bangga akan keragaman bangsa Indonesia. & 3,51 \\
& \multicolumn{1}{c}{ Rasa Bangga terhadap Tanah Air } & 3,66 \\
\hline
\end{tabular}

Kebanggaan siswa terhadap tanah air tercermin pada struktur keluarga, dimana mereka sudah turun temurun berdomisili di daerah kepulauan dan pada umumnya masyarakat menggunakan produk anak bangsa dalam sehari-hari, baik sandang maupun papan.
Pada umumnya responden (siswa) dan guru adalah orang kepulauan serta memiliki keragaman yang berbeda-beda (etnis). Tetapi mampu membangun keutuhan dan kebersamaan. Sehingga, karakter siswa dengan melihat rasa bangga terhadap tanah air terkategori Sedang.

\begin{tabular}{clr}
\hline NO & \multicolumn{1}{c}{ INDIKATOR } & TINGKAT \\
\hline B13 & $\begin{array}{l}\text { Saya senang dengan sikap orang Indonesia yang tinggal } \\
\text { di luar negeri namun tetap bangga dengan Indonesia } \\
\text { Saya merasa terganggu ketika sekolah memaksakan } \\
\text { peserta didik menyanyikan lagu Indonesia Raya untuk } \\
\text { melahirkan patriotisme }\end{array}$ & 2,56 \\
B15 & $\begin{array}{l}\text { Saya harus berprestasi untuk kemajuan bangsa } \\
\text { Indonesia }\end{array}$ & 3,77 \\
B16 & $\begin{array}{l}\text { Saya terharu melihat bendera merah putih berkibar di } \\
\text { event internasional }\end{array}$ & 3,64 \\
& \multicolumn{1}{c}{ Kepekaan Psikologis } & 3,75 \\
\hline
\end{tabular}

Secara sikologis responden (siswa) merasa senang ketika menyanyikan lagu Indonesia Raya setiap Upacara Bendera (senin) yang disertai dengan pengibaran bendera merah putih, jadi kecintaan siswa terhadap menyanyikan Indonesia Raya bukan karena adanya unsur pemaksanaan.
Masih terdapat kebimbangan responden (siswa) terhadap orang yang tinggal di luar negeri tetapi masih bangga dengan Indonesia. Sehinggatingkat Karakter Siswa terhadap kelekatan sikologis terkategori Sedang.

\begin{tabular}{clc}
\hline NO & \multicolumn{1}{c}{ INDIKATOR } & TINGKAT \\
\hline B17 & $\begin{array}{l}\text { Saya wajib berjuang membela negara berdasarkan } \\
\text { Pancasila dan UUD ‘45 }\end{array}$ & 3,51 \\
B18 & $\begin{array}{l}\text { Saya komitmen terhadap Negara Kesatuan Republik } \\
\text { Indonesia. }\end{array}$ & 3,87 \\
B19 & $\begin{array}{l}\text { Saya bangga dengan semboyan Bhinneka Tunggal Ika. } \\
\text { Saya bersedia mendamaikan konflik antar suku dan } \\
\text { B20 }\end{array}$ & 3,41 \\
& agama & 3,55
\end{tabular}


Responden (siswa) memiliki kecintaan dan semangat yang tinggi terhadap Negara Kesatuan Republik Indonesia (NKRI), walaupun mereka belum memahami secara utuh tentang Ideologi Negara dan semboyan Bhinneka Tunggal Ika. Tetapi siswa sudah memiliki rasa tanggungjawab untuk membela Negara dan melawan penyebaran berita-berita bohong.

Berdasarkan indikator diatas, menunjukkan bahwa tingkat karakter siswa terhadap berjuang dan membela negara,

Kemandirian

\begin{tabular}{clr}
\hline NO & \multicolumn{1}{c}{ INDIKATOR } & TINGKAT \\
\hline C1 & Saya merapihkan tempat tidur setelah bangun tidur & 3,41 \\
C2 & Saya berdoa sebelum dan setelah makan & 3,63 \\
C3 & Saya pergi ke sekolah tanpa merepotkan orang lain & 3,54 \\
C4 & Saya menyiapkan diri untuk pembelajaran esok hari & 3,39 \\
\multicolumn{2}{c}{ Kemandirian di Rumah } & 3,49 \\
\hline
\end{tabular}

Kemandirian yang biasanya dilakukan dirumah merupakan hal yang terpenting untuk diketahui dan diaplikasikan bagi setiap siswa. Untuk memperkuat dalam implementasinya diperlukan adanya pembiasaan dilingkungan keluarga, agar mudah diaplikasikan secara rutin. bangga dengan semboyan dan bersedia mendamaikan serta melawan penyebaran berita bohong terkategori Sedang.

Secara keseluruhan responden (siswa) memiliki rasa cinta dan bangga terhadap Tanah Air serta memiliki kepekaan dan komitmen yang tinggi terhadap negara, sehingga secara keseluruhan tingkat Karakter siswa terhadap Nasionalisme terkategori Sedang $(3,59)$.

\begin{tabular}{llr}
\hline NO & \multicolumn{1}{c}{ INDIKATOR } & TINGKAT \\
\hline \multirow{2}{*}{ C5 } & $\begin{array}{l}\text { Saya segera masuk kelas sebelum bel pelajaran pertama } \\
\text { berbunyi }\end{array}$ & 3,42 \\
C6 & Saya mengikuti pelajaran dengan sungguh-sungguh & 3,70 \\
C7 & $\begin{array}{l}\text { Saya berusaha menyelesaikan tugas di kelas tepat waktu } \\
\text { C8 }\end{array}$ & $\begin{array}{l}\text { Saya melakukan kegiatan yang bermanfaat saat waktu } \\
\text { istirahat } \quad \text { Kemandirian di Sekolah }\end{array}$ \\
& & 3,45 \\
& & 3,19 \\
\hline
\end{tabular}

Kegiatan kemandirian siswa saat disekolah terdapat beberapa kebiasaan yang dilakukan, diantaranya: masuk kelas
Diantara indikator diatas, terdapat dua kemandirian dirumah yang belum dapat diaplikasikan secara rutin, yaitu: menyiapkan diri untuk persiapan pembelajaran esok hari dan merapikan tempat tidur. Sehingga, tingkat karakter siswa terhadap kemandirian di rumah terkategori Sedang. 
dan melakukan kegiatan yang bermanfaat saat istirahat.

Indikator diatas menunjukkan, bahwa pembiasaan dalam memanfaatkan waktu istirahat secara keseluruhan siswa belum dapat mengaktualisasikan sehari-hari di sekolah. Masih terdapat beberapa siswa lebih fokus pada main dan bercerita. Untuk tingkat karakter siswa dalam kemandirian disekolah terkategori Sedang.

\begin{tabular}{clr}
\hline NO & \multicolumn{1}{c}{ INDIKATOR } & TINGKAT \\
\hline C9 & Saya memilih teman dengan tepat & 3,15 \\
C10 & Saya menolak ketika diajak membolos & 3,63 \\
C11 & Saya mengingatkan teman ketika waktu bermain habis & 3,21 \\
& Kemandirian dalam Pergaulan Sosial & 3,33 \\
\hline
\end{tabular}

Pada aspek pergaulan sosial terdapat tiga indikator kemandirian yang sering kali terjadi di lingkungan sekolah dan masyarakat. Namun, sebahagian besar responden (siswa) menyatakan sangat setuju apabila menolak ajakan bolos. Lain halnya dengan memilih teman dengan tepat dan mengingatkan teman saat waktu bermain usai.

Fenomena di lingkungan sekolah dan masyarakat dalam pemilihan teman dengan tepat, terkadang dilakukan kaum perempuan dibanding laki-laki, begitupun halnya dengan mengingatkan teman saat waktu bermain telah habis. Untuk mengetahui tingkat karakter siswa pada aspek pergaulan sosial terkategori Sedang.

Berdasarkan indikator diatas, dengan berbagai aspek kemandirian dirumah, sekolah dan pergaulan sosial terdapat beberapa variasi tingkat karakter responden (siswa). Sehungga secara keseluruhan menunjukkan tingkat karakter siswa pada indikator kemandirian terkategori Sedang $(3,42)$.

\section{Gotong Royong}

\begin{tabular}{clr} 
NO & INDIKATOR & TINGKAT \\
\hline D1 & Saya menjenguk teman yang terkena musibah & 3,54 \\
D2 & Saya membuang sampah pada tempatnya & 3,63 \\
D3 & Saya memberikan bantuan bagi korban bencana alam & 3,36 \\
& Peduli Lingkungan & 3,51 \\
\hline
\end{tabular}

Kepedulian responden (siswa) terhadap lingkungan terlihat sangat menggembirakan, walaupun kenyataannya belum semua siswa dapat mengaplikasikan secara maksimal. Tetapi hal ini sudah menunjukkan, bahwa peduli lingkungan sangat berarti dan bermanfaat untuk kebutuhan manusia.

Hal ini menggambarkan bahwa kesadaran siswa terhadap kepedulian lingkungan sudah melekat, sehingga tingkat karakter siswa dalam hal kepedulian terkategori Sedang.

\begin{tabular}{clr}
\hline NO & \multicolumn{1}{c}{ INDIKATOR } & TINGKAT \\
\hline D4 & $\begin{array}{l}\text { Saya belajar kelompok untuk memperoleh prestasi yang } \\
\text { lebih baik }\end{array}$ & 3,37 \\
D5 & Saya terlibat dalam kepengurusan organisasi di sekolah & 3,37
\end{tabular}


D6

Saya mengambil keputusan tanpa mendiskusikannya

dengan siapapun

D7 Saya ingin meraih kesuksesan bersama teman-teman

Keinginan Meraih Sukses Bersama

Meraih kesuksesan bersama merupakan hal yang sangat baik dalam pertemanan dan ini memerlukan komitmen yang kuat dalam meraih kesuksesan bersama. Kecendrungan responden dalam melakukan pembelajaran kelompok lebih efektif dibanding perorangan dalam memperoleh prestasi yang lebih baik.
Sikap otoriter merupakan hal yang kurang baik diterapkan dalam organisasi, karena memiliki dampak sikologis terhadap teman-teman. Sehingga, siswa memiliki kecendrungan dalam mengambil/ mengeluarkan suatu keputusan harus dengan jalan demokrasi. Adapun tingkat karakter siswa pada aspek meraih kesuksesan bersama terkategori Sedang.

\begin{tabular}{clr}
\hline NO & \multicolumn{1}{c}{ INDIKATOR } & TINGKAT \\
\hline D8 & $\begin{array}{l}\text { Saya siap memilih dalam kepengurusan organisasi di } \\
\text { sekolah }\end{array}$ & 3,39 \\
D9 & $\begin{array}{l}\text { Saya berani menyampaikan pendapat yang berbeda } \\
\text { dengan orang lain }\end{array}$ & 3,40 \\
D10 & Saya menerima kritik orang lain tanpa membencinya & 3,59 \\
\multicolumn{2}{c}{ Interaksi Sosial yang saling Membutuhkan (Interdepedensi) } & 3,46 \\
\hline
\end{tabular}

Sikap sportifitas telah tertanam dalam diri siswa yang diaktualisasikan lewat menerima kritikan tanpa ada rasa benci dan memiliki sikap percaya diri dalam menyampaikan suatu pendapat serta memiliki kepedulian terhadap kepengurusan organisasi sekolah. Pada hakikatnya responden (siswa) dalam berinteraksi sosial yang saling membutuhkan memiliki tingkat karakter dengan kategori Sedang.

\begin{tabular}{llr}
\hline NO & \multicolumn{1}{c}{ INDIKATOR } & TINGKAT \\
\hline D11 & $\begin{array}{l}\text { Saya bersama teman-teman mencari solusi atas masalah } \\
\text { yang dihadapi }\end{array}$ & 3,65 \\
D12 & $\begin{array}{l}\text { Saya tidak nyaman menyelesaikan tugas sekolah secara } \\
\text { bersama-sama dengan teman saya }\end{array}$ & 2,75 \\
& \multicolumn{1}{c}{ Pemecahan Masalah Kolektif } & 3,20 \\
\hline
\end{tabular}

Penyelesaian suatu permasalahan yang dihadapi siswa terkadang mencari solusi secara bersama-sama. Pola seperti ini yang diaktualisasikan siswa dalam menghadapi suatu permasalahan. Beda halnya dengan penyelesaian tugas sekolah, terkadang siswa bersikap fleksibeal. Terkadang ada yang merasa nyaman apabila tugas sekolah dilaksanakan secara individu begitupun juga secara kelompok.

Berdasarkan tabel diatas, menunjukkan bahwa tingkat karakter siswa dengan melihat beberapa indikator pada aspek pemecahan masalah secara kolektif terkategori Sedang.

Secara keseluruhan tingkat karakter siswa terhadap gotong royong dengan 
melihat beberapa indikator pada aspek peduli lingkungan, meraih kesuksesan bersama, interaksi sosial yang saling

\section{Integritas}

\begin{tabular}{clr}
\hline NO & \multicolumn{1}{c}{ INDIKATOR } & TINGKAT \\
\hline E1 & $\begin{array}{l}\text { Saya ingin apa yang dipikirkan sesuai dengan apa yang } \\
\text { dirasakan }\end{array}$ & 3,43 \\
& $\begin{array}{l}\text { Saya berusaha melakukan aktivitas sesuai dengan apa } \\
\text { E2 }\end{array}$ & $\begin{array}{l}\text { yang saya pikirkan } \\
\text { Saya akan mempertahankan diri selama saya benar, } \\
\text { demikian juga sebaliknya }\end{array}$ \\
$\quad$ Aspek Kejujuran & 3,34 \\
& $\quad 3,42$ \\
\hline
\end{tabular}

Responden (siswa) memiliki sikap konsisten dalam bertindak dan memiliki prinsip dalam mempertahankan suatu kebenaran. Hal semacam ini merupakan modal besar dalam membudayakan atau membiasakan bersikap jujur dengan berbagai tindakan. Dalam menanamkan membutuhkan dan memecahkan masalah secara kolektif terkategori Sedang $(3,36)$.

\begin{tabular}{clr}
\hline NO & \multicolumn{1}{c}{ INDIKATOR } & TINGKAT \\
\hline E4 & $\begin{array}{l}\text { Saya izin kepada orang tua ketika pulang sekolah } \\
\text { terlambat }\end{array}$ & 3,27 \\
E5 & $\begin{array}{l}\text { Saya senang melaksanakan tugas dan kewajiban sesuai } \\
\text { dengan keputusan musyawarah }\end{array}$ \\
E6 & $\begin{array}{l}\text { Saya menjaga amanat guru untuk melaksanakan tugas } \\
\text { belajar sesuai jadwal } \\
\text { Saya siap membela kebenaran yang disepakati oleh siswa } \\
\text { E7 }\end{array}$ & 3,56 \\
& $\quad$ Aspek Amanah & 3,47 \\
\hline
\end{tabular}

kejujuran para siswa telah menunjukkan, pada tiga indikator integritas.

Berdasarkan indikator diatas, siswa telah memahami bagaimana pentingnya sebuah kejujuran terhadap manusia. Sehingga, tingkat karakter siswa pada aspek kejujuran terkategori Sedang.
Amanah merupakan sebuah tanggungjawab yang serahkan kepada seseorang dan harus dilaksanakan sesuai dengan harapan pemberi amanah. Permintaan izin dan melaksanakan tugas sesuai dengan musyawarah serta siap membela kebenaran merupakan sikap yang terpuji.
Namun, dalam aspek amanah pada indikator izin kepada orang tua, masih memerlukan pembiasaan agar siswa secara keseluruhan mampu mengaplikasikan apabila terlambat pulang sekolah. Sehingga tingkat karakter siswa pada aspek amanah terkategori Sedang.

\begin{tabular}{clr}
\hline NO & \multicolumn{1}{c}{ INDIKATOR } & TINGKAT \\
\hline \multirow{2}{*}{ E8 } & $\begin{array}{l}\text { Saya pamit kepada orang tua sebelum berangkat ke } \\
\text { sekolah }\end{array}$ & 4,11 \\
& $\begin{array}{l}\text { Saya menahan diri untuk tidak menggunjing guru dalam } \\
\text { E9 }\end{array}$ & setiap situasi. \\
E10 & Saya menyimak penjelasan guru di dalam kelas & 3,17 \\
E11 & Saya meneladani kakak kelas yang baik & 3,60 \\
\end{tabular}


Saya siap melindungi adik kelas dari perbuatan yang

E12 mengganggu ketentraman diri

Saya akan selalu menghargai dan membantu para

E13 penyandang cacat

Aspek Hormat atau Menghargai

Saling hormat menghormati dan menghargai merupakan budaya yang perlu dikembangkan kepada semua lapisan masyarakat. Budaya semacam ini tumbuhnya lewat lingkungan keluarga, sekolah dan masyarakat. Sehingga setiap generasi bangsa wajib mengaplikasikan dimana dan kapan saja.

Harapan orang tua dan guru sangat
besar apabila siswa dapat mengaktualisasikan dalam sehari-hari, baik mdi tengah-tengah keluarga, masyarakat dan sekolah. Sehingga tingkat karakter siswa dengan melihat beberapa indikator diatas, terkategori Sedang.

\begin{tabular}{|c|c|c|}
\hline $\mathrm{NO}$ & INDIKATOR & TINGKAT \\
\hline E14 & $\begin{array}{l}\text { Saya mengerjakan tugas yang diberikan guru sampai } \\
\text { tuntas }\end{array}$ & 3,60 \\
\hline E15 & Saya mematuhi peraturan dan tata tertib sekolah & 3,65 \\
\hline E16 & $\begin{array}{l}\text { Saya membayarkan uang sekolah yang dititipkan orang } \\
\text { tua }\end{array}$ & 3,75 \\
\hline E17 & $\begin{array}{l}\text { lain } \\
\text { late }\end{array}$ & 3,15 \\
\hline E18 & Saya mencontek saat tes atau ujian sekolah & 3,29 \\
\hline E19 & Saya berusaha menjadi teladan bagi teman-teman & 3,44 \\
\hline \multicolumn{2}{|r|}{ Aspek Bertanggungjawab } & 3,5 \\
\hline
\end{tabular}

Pada prinsipnya semua siswa akan berupaya menyelesaikan semua tugas-tugas yang diberikan oleh guru, mematuhi semua aturan sekolah, menyelesaikan kewajiban terhadap sekolah dan berusaha menjadi tauladan terhadap teman-teman. Untuk dapat mewujudkan tanggungjawab memerlukan proses yang panjang dan dibutuhkan pembiasaan baik dilingkungan keluarga, sekolah maupun masyarakat.

Pada aspek tanggungjawab terdapat satu indikator yang masih susah untuk menghindari agar tidak meniru tugas orang lain. Sehingga, tingkat karakter siswa terkategori Sedang.

\begin{tabular}{clc}
\hline NO & \multicolumn{1}{c}{ INDIKATOR } & TINGKAT \\
\hline \multirow{2}{*}{ E20 } & $\begin{array}{l}\text { Saya mengucapkan selamat kepada teman yang terpilih } \\
\text { pengurus OSIS }\end{array}$ & 3,47 \\
E21 & $\begin{array}{l}\text { Saya menerima hukuman atas kesalahan yang saya } \\
\text { lakukan }\end{array}$ & 3,67 \\
E22 & $\begin{array}{l}\text { Saya menerima perbedaan teman dalam pergaulan tanpa } \\
\text { membedakan status sosial }\end{array}$ & 3,65 \\
E23 & Saya protes terhadap perlakuan yang diskriminatif & 3,47 \\
& $\quad$ Aspek Adil & 3,6 \\
\hline
\end{tabular}


Menegakkan suatu kebenaran dan sportifitas dalam berbagai hal serta menerima suatu perbedaan tidaklah mudah. Tetapi dengan melihat responden (siswa) dengan menyikapi rasa keadilan yang tertuang pada tabel diatas, mereka sangat setuju menanamkan sikap adil dilingkungan keluarga, sekolah dan masyarakat.

Terdapat dua indikator pada aspek adil yang memerlukan penguatan, agar siswa mampu sepenuhnya memberikan ucapan selamat kepada teman yang berhasil dan memberikan penguatan pembelaan pada hal yang sifatnya diskriminatif. Sehingga karakter siswa pada aspek adil terkategori Sedang.

Berdasarkan integritas diatas dengan melihat berbagai aspek kejujuran, amanah, menghormati dan menghargai, bertanggungjawab, dan adil. Maka, secara keseluruhan tingkat karakter siswa terkategori Sedang $(3,49)$.

Berdasarkan hasil entri tabulasi data, hitung sampel, dan analisis karakter dengan mengukur tingkat indeks karakter siswa di Provinsi Maluku dengan 3 wilayah kabupaten, 11 sekolah (SMA), dan 110 responden (siswa). Dengan melihat beberapa aspek dan indikator (religiusitas, nasionalisme, kemandirian, gotong royong, dan integritas). Maka, tingkat respon siswa dengan melihat/memilih beberapa indikatori karakter terkategori Sedang $(3,48)$.

\section{Faktor Pendukung Dan Penghambat}

Implementasi pendidikan karakter tidak terlepas dari peran lingkungan keluarga, masyarakat, dan sekolah. Karena ketiga aspek ini sangat menentukan dalam mewujudkan pendidikan karakter. Penguatan karakter melalui pembiasaan dan didukung oleh anggota keluarga, pengelola lembaga pendidikan (sekolah), dan khalayak.

Berdasarkan aspek diatas, yang utama adalah bagaimana peran orang tua dan keluarga dalam sehari-hari dapat memberikan bimbingan dan pembinaan yang sifatnya positif, terutama pada pengenalan masalah keyaqinan terhadap ajaran agama, diantaranya: ibadah dan akhlak.

Pada umumnya lembaga pendidikan tingkat menengah (SMA) memiliki simbolsimbol kenegaraan pada masing-masing ruang, pelaksanaan upacara bendera yang disertai menyanyikan lagu Indonesia Raya merupakan kegiatan rutin atau program sekolah setiap hari senin, dan tidak terpengaruh dengan produk luar, serta yang tak kalah pentingnya yaitu: sangat bangga sebagai orang Indonesia dan tinggal di Indonesia.

Menyelesaikan tugas di rumah tanpa menunggu perintah atau instruksi dan menyelesaikan tugas sekolah dengan tepat waktu. Dan sudah mampu memenfaatkan kegiatan pada waktu istirahat di sekolah maupun dirumah agar tidak lagi merepotkan orang lain.

Kerjasama atau saling membantu diantara sesama merupakan hal yang sangat penting dalam kehidupan sosial kemasyarakatan dan keagamaan. Makanya, responden sangat setuju apabila sering membantu orang lain yang mendapatkan musibah serta sama-sama menjaga kebersihan dilingkungan keluarga, masyarakat, dan sekolah.

Pemahaman dan pengalaman sikap jujur, tanggungjawab, amanah, dan adil merupakan konsep keselamatan apabila kita mampu mengaplikasikan. Perwujudan konsep ini, harus diawali di lingkungan keluarga, penguatan lewat sekolah, dan diaktualisasikan , di lingkungan masyarakat.

Sikap dan perilaku, pemahaman dan pengalaman agama orang tua, guru, dan masyarakat sangat berpengaruh dalam membentuk prilaku peserta didik, Kegiatan keagamaan yang dilaksanakan pada lembaga di luar sekolah sangat berperan dalam memupuk sikap religiusitas. Efektifitas dan efesiensinya suatu proses belajar mengajar apabila manajemen sekolah mampu membangun budaya iklim yang ramah, bersahabat dan kondusif yang bernuansa intelektualitas dan profesional. 


\section{PENUTUP}

Berdasarkan hasil uraian diatas, menunjukkan bahwa tingkat karakter siswa kelas XII pada jenjang SMA yang tersebar di Kabupaten Seram Bagian Barat, Maluku Barat Daya, dan Maluku Tengah Provinsi Maluku. Dengan melihat lima dimensi religiusitas, nasionalisme, kemandirian, gotong royong, dan integritas. Maka, indeks karakter siswa SMA terkategori Sedang $(3,48)$.

Tingkat karakter siswa dengan melihat dimensi religiusitas tergolong kategori "Sedang", dengan melihat aspek kepercayaan, sosial dan keagamaan. Tingkat karakter siswa pada dimensi nasionalisme terkategori "Sedang", yang mencakup aspek rasa cinta tanah air, bangga terhadap tanah air, kepekaan psikologi dan komitmen terhadap negara.

Tingkat karakter siswa dengan melihat dimensi kemandirian dengan kategori "Sedang", dengan melihat aspek kemandirian dirumah dan sekolah, serta pergaulan sosial. Tingkat karakter siswa pada dimensi gotong royong adalah terkategori "Sedang" yang mencakup dengan kepedulian lingkungan, meraih kesuksesan bersama, interaksi sosial yang saling membutuhkan, dan mencari solusi secara kolektif. Sedangkan tingkat karakter pada dimensi integritas tergolong kategori "Sedang", dengan melihay beberapa aspek diantarnya: kejujuran, amanah, Hormat menghormati dan saling menghargai, bertanggungjawab dan adil.

\section{UCAPAN TERIMA KASIH}

Penulis menghaturkan ucapan terima kasih kepada Kepala Balai Penelitian dan Pengembangan Agama Makassar yang telah mengamanatkan dan memberikan kesempatan kepada penulis untuk ikut terlibat dalam melakukan penelitian ini di Provinsi Maluku. Terima kasih juga penulis sampaikan kepada Kepala Kantor Kementerian Agama Provinsi Maluku dan Kementerian Agama Kabupaten/Kota yang menjadi lokasi dalam penelitian ini serta bersama seluruh jajarannya yang telah memfasilitasi dan mendampingi peneliti dalam pengumpulan data. Tak lupa pula penulis mengucapkan terima kasih kepada segenap kepala madrasah, dan kepala sekolah baik negeri maupun swasta atas kesediaannya menerima dan mengisi angket yang telah peneliti edarkan di madrasah dan sekolah masing-masing. Selanjutnya penulis juga memberikan apresiasi dan ucapan terima kasih kepada bapak Amiruddin di samping sebagai peneliti madya juga sebagai koordinator bidang pendidikan agama dan keagamaan yang selalu meluangkan waktu dan memberikan support kepada penulis dalam menyelesaikan tulisan ini. Akhirnya kepada TIM Pengelola Jurnal Educandum penulis juga menyampaikan terima kasih telah berkenan memuat tulisan ini.

\section{DAFTAR PUSTAKA}

Azizah, Nur, 2003. "Perilaku Moral Dan Religiusitas Siswa Berlatar Belakang Pendidikan Umum dan Agama". Jurnal Psikologi, Fakultas Psikologi Universitas Gaja Mada. 33 (2): $1-8$

Aryani, S. A. 2017. Healthy-Minded Religous Phenomenon Shalawatan: A Study On The Three Majelis Shalawat In Java Indonesian Journal Of Islam and Muslim Societies. $\quad$ https://doi.org/ 10.18326/ijims.v7i1.1-30.

Berscheid, E. Graziano, W. Monson, T, \& Dermer, M. 1976. Outcome Depedency: Attention, Attribution, and Attractions. Journal Of Personality and Social Psykology. https://doi.org/10.1037/00223514.34.5.978.

Boyle, G. J. Saklofske, D. H, \& Matthews, G. 2015. Measures Of Personality and Social Psychological Constructs. https://doi.org/10.1016/C2010-0$\underline{68427-6}$ 
Cacioppo, J.T. Visser, P. S, Lengyel, P. Peterson, M. B. Schildkraut, D. J. Lavine, H. Power. 2014. Political Psychology. Political Psychologi. https://doi.org/10.1017/S15375920 4040575.

Farid, Muhammad, and Evi Aviyah, 2014. "Religiusitas, Kontrol Diri dan Kenakalan Remaja". Persona, Jurnal Psikologi Indonesia 3 (2): 126-29.

Hasan, N. 2012. Piety, Politcs, and PostIslamism: Dhikr Akbar In Indonesia. Al-Jamiah: Journal Of Islamic Studies. https://doi.org/ 10.14421/ajis.2012.502.369-390

Kusdiana, Evi, M. As'ad Djalali, and M Farid. 2018. "Percaya Diri Religiusitas Dan Perilaku Menyontek." Jurnal Konseling Indonesia 3 (2): 37-41

Kelley, H. \& Thibaut, J. 1980. Interpersonal Relation: A Theory Of Interdepedence. Oxford University Press. https://doi.org/10.1093/sw/25.3.245

King, P. E, \& Furrow, J. L. 2004. Relegion as a Resource For Positive Youth Devlopment: Religion, Social Capital, and Moral Outcomes Developmental Psyhology, 40 (5), 703-713.

https://doi.org/10.1037/00121649.40.5.703

Naim, N. 2016 Mengembalikan Misi Pendidikan Sosial Dan Kebudayaan Pesantren. Jurnal Pendidikan Islam. $\quad$ https://doi.org/10.15575/ jpi.v27i3.528

Pearce, L. D. Hayward, G. M. \& Pearlman, J. A. 2017. Measuring Five Dimension of Religiosity Across Adolescence. Review of Religious Research. https://doi.org/ 10.1007/s13644-017-0291-8.

Reza, Iredho Fani. 2013. "Hubungan Antara Religiusitas Dengan Moralitas Pada Remaja Di Madrasah Aliyah (MA)". Humanitas 10 (2): 45-58.
Shaver, K. G, 1987. Principles Of Social Psychology

Sherman, D. K, \& Cohen, G. L. 2006. The Psychology Of Self-defence: SelfAffirmation Theory. Advances In Experimental Social Psychology. 38 (06), 183-242. https://doi.org/ 10.1016/S0065-2601 (06)38004-5

Smith, P. K. \& Magee, J. C. 2015. The Interpersonal Nature Of Power and Status. Current Opinion In Behavioral Sciences. https://doi.org/ 10.1016/j.cobeha.2015.04.007

Stangor, C. \& Leary, S. P. 2006. Intergroup Beliefs: Investigation From The Social Side. Advances In Experimental Social Psyhology. 38(06), 243-281. https://doi.org/ 10.1016/S0065-2601(06)38005-7

Yunus R. 2014. Nilai-Nilai Kearifan Lokal (local Genius) Sebagai Penguat karakter Bangsa Study Empiris Tentang Huyula.

Muzhofar, Akhwan, 2014. Pendidikan Karakter: Konsep Dan Implementasinya Dalam Pembelajaran Di Sekolah/ Madrasah. EI Tarbawi Vol.7 No.1 2014

Hendarman, 2017. Konsep Dan Pedoman Penguatan Pendidikan Karakter, Pusat Analisis Dan Singkronisasi Kebijakan. Jakarta: Sekertariat Jenderal, Kementerian Pendidikan dan Kebudayaan

M. Furqon, Hidayatullah, 2010. Guru Sejati: Membangun Insan Berkarakter Kuat dan Cerdas. Surakarta: Yuma Pustaka

Kementerian Pendidikan Nasional, 2011. Panduan Pelaksanaan Pendidikan Karakter. Jakarta: Badan Penelitian dan Pengembangan, Pusat kurikulum dan Perbukuan. 